\title{
(10) AACE JOURNALS

Prevalence and Characteristics of Adrenal Tumors and Myelolipomas in Congenital Adrenal Hyperplasia: A Systematic Review and Meta-Analysis

\begin{tabular}{|r|l|}
\hline Journal: & AACE Journals \\
\hline Manuscript ID & Draft \\
\hline Manuscript Type: & EP - Review Article \\
\hline Keywords: & $\begin{array}{l}\text { Adrenal Hyperplasia, Congenital, Adrenogenital Syndrome, Adrenal, } \\
\text { Adrenal Gland Diseases }\end{array}$ \\
\hline
\end{tabular}


Prevalence and Characteristics of Adrenal Tumors and Myelolipomas in Congenital Adrenal Hyperplasia: A Systematic Review and MetaAnalysis 


\begin{abstract}
Context: The prevalence of adrenal tumors in congenital adrenal hyperplasia $(\mathrm{CAH})$ is uncertain.
\end{abstract}

Objective: To estimate the prevalence and characteristics of adrenal tumors and myelolipoma in $\mathrm{CAH}$, and investigate clinical features of this population.

Data Sources Methods: Systematically searches in Medline Ovid and Embase for articles published until January 2020.

Study Selection: Studies with confirmed CAH, biochemically and/or genetically, were included.

Data Extraction: The two authors independently extracted data from each study.

Results: Six cohort studies were included in the prevalence calculation. In addition, 32 case reports on adrenal myelolipomas and $\mathrm{CAH}$ were included. The prevalence of adrenal tumors in $\mathrm{CAH}$ was $29.3 \%$. When only studies with genetically verified CYP21A2 mutations were included the prevalence was $23.6 \%$. The prevalence of myelolipoma in CAH was $7.4 \%$ (verified CYP21A2 mutations 8.6\%). The proportion of myelolipoma in the adrenal tumors was $25.4 \%$ (genetically verified $36.6 \%$ ). The median (range) age at tumor diagnosis was 36.0 (12-60) years and there were more tumors in males than in females (37.9\% vs. $22.1 \%$, $\mathrm{P}<0.05$ ). In patients with myelolipomas $95.7 \%$ had an undiagnosed or poorly managed $\mathrm{CAH}$.

Conclusion: Patients with CAH had a high prevalence of adrenal tumors, particularly myelolipoma. Those with myelolipomas had a high frequency of late diagnosed or poorly controlled CAH. Adrenal imaging may be considered in patients with $\mathrm{CAH}$, especially if abdominal pain is present. 


\section{INTRODUCTION}

Congenital adrenal hyperplasia $(\mathrm{CAH})$ is an autosomal recessive disorder with impaired synthesis of adrenal glucocorticoids with impaired cortisol and aldosterone production. Mutations in the CYP21A2 gene result in 21-hydroxylase deficiency (21OHD) which is by far the most common variant of CAH $(95-99 \%)(1,2)$.

CAH is divided into classical, which includes the salt-wasting (SW) and simple virilizing (SV) forms, and the nonclassical form (NC). Other less common variants are $11 \beta 1$ -

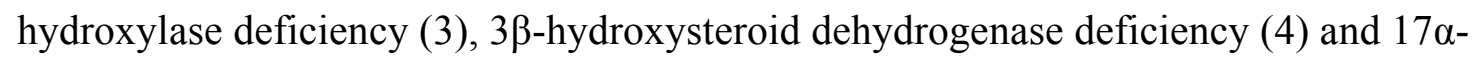
hydroxylase deficiency (5), but more uncommon variants exists as well $(6,7)$. Almost all $\mathrm{CAH}$ variants will result in increased ACTH production from the pituitary gland due to negative feedback from the adrenals. In most CAH variants, including 21OHD, ACTH stimulates increased androgen production from the adrenals causing virilization in affected girls but also in male toddlers with SV if no neonatal screening has been done (8). ACTH is also a growth factor to the adrenals enhancing adrenal growth with large adrenals, hyperplasia, in CAH when untreated. Whether ACTH hypersecretion also cause tumor growth is uncertain. Few studies have systematic investigated the adrenals radiologically in patients with $\mathrm{CAH}(9,10)$, and routine screening for adrenal masses in $\mathrm{CAH}$ are not recommended (11). One study found increased frequency of adrenal adenoma in $11 \%$ of patients with CAH (10), particularly adrenal myelolipomas, while an older study found an even higher frequency $(83 \%)(9)$.

Myelolipomas are benign tumors of the adrenal cortex with adrenal, adipose and myeloid components (12). They are often hormonal inactive and were previously considered to be rare. However, the reported number of myelolipomas in patients with $\mathrm{CAH}$ has increased during the last years, probably due to the increased use of abdominal imaging. With this increased 
use of abdominal imagining adrenal tumors in general also have been found to be common in the elderly with a prevalence of up to $15 \%(13)$, but much lower in the younger population, especially below 40 -years of age. The majority are benign adrenal adenomas with no hormone excess production (14). One meta-analysis estimated a prevalence of biochemically diagnosed $\mathrm{CAH}$ in incidentalomas to $5.9 \%$, however, it was reduced to only $0.8 \%$ when only patients with genetically verified CAH were included (15). Screening for CAH with 17-hydroxyprogesterone (17OHP) has been recommended in patients with bilateral adrenal incidentalomas (16).

The aim of this systematic review and meta-analysis was to investigate the prevalence of adrenal tumors in $\mathrm{CAH}$ with a special focus on myelolipomas. We also wanted to characterize the patients with $\mathrm{CAH}$ and concurrent adrenal tumor as well as investigate if there is evidence to recommend regular adrenal imaging in the follow-up of $\mathrm{CAH}$.

\section{Methods}

\section{Search Strategy}

All studies published on the topic adrenal tumors and CAH was included with no restriction on age or language. Meeting abstracts were excluded but case reports about $\mathrm{CAH}$ and adrenal tumors was included. Systematic searches were performed using Medline Ovid from 1984 and Embase until 31 December 2019 using the following search strategy “(adrenal adj3 (cancer* or neoplasm* or tumor* or tumour* or incidentaloma* or nodule* or pheochromocytoma* or mass or masses or myelolipoma* or cushing)).mp", “conn adenoma*. Mp”, "primary hyperaldosteronism. Mp or Hyperaldosteronism/" in search one and “congenital adrenal hyperplasia.mp”, “21-hydroxylase deficiency.mp”, “CYP 21A2. Mp”, “11-hydroxylase deficiency.mp", "3 beta hydroxysteroid dehydrogenase deficiency. mp" and "17-alfa 


\section{Selection criteria}

The inclusion criteria was a confirmed CAH diagnosis, e.g. 21-hydroxylase deficiency was verified with high 17-hydroxyprogesterone (17OHP) $\geq 30 \mathrm{nmol} / \mathrm{L}$ and/or CYP21A2 mutations and/or had a typical clinical presentation of CAH (17). If the same group had presented several studies, we only included the patients once. We also identified other types of CAH than 21OHD with myelolipoma. Both authors did the literature search independently and a university librarian helped with the search. Disagreements were solved by consensus.

A quality assessment of the studies of $\mathrm{CAH}$ and adrenal tumors was incorporated with our comments on the strength and limitations by free text. No formal quality assessment tool was used since none has been developed to study prevalence or case reports. The PRISMA guidelines were followed (18).

\section{Data extraction}

The two authors independently extracted data from each study. The following information was recorded from each study: first author, publication year, country, title, number of patients with $\mathrm{CAH}$ and tumors, $\mathrm{CAH}$ variant and diagnostic criteria for the $\mathrm{CAH}$ diagnosis. 
From the individual cases we extracted: gender, age at adrenal tumor diagnosis and $\mathrm{CAH}$ diagnosis, CAH variant, 17OHP values, genetic analyses, tumor classification, largest diameter of the tumor, tumor side and/or if bilateral and treatment. If data was missing the corresponding author of the studies was contacted.

\section{Statistical Analysis}

Results were calculated after merging data from all studies. In the meta-analysis the results were given as median and range. Pearson's Chi square test was used to compare the prevalence of adenoma in men and woman and side of tumor and to compare the prevalence of myelolipoma in the patients and the normal population. The prevalence of myelolipoma at age 40 in the normal population was calculated to $0.32 \%$ ( $8 \%$ of the adrenal adenoma which have a prevalence of 4\%) (19).To compare continues variables $t$-test were used while Chi square or Fischer Exact test were used for categorical variables. Statistical significance was accepted for $P<0.05$.

\section{Results}

The Medline Ovid and Embase searches identified 676 publications, of which 195 were duplicates. Forty-seven publications were considered eligible for inclusion. Only seven of these studies investigated the prevalence of adrenal tumors in $\mathrm{CAH}(9,10,20-24)$. Two of them reported on the same patient cohort $(9,20)$ so only the most recent study was used in the meta-analysis (9). These six cohort studies included 215 patients and 63 of them had an adrenal tumor. Three of the studies $(9,22,24)$ had defined an adrenal mass $\geq 5 \mathrm{~mm}$ but we also extracted data on tumors $\geq 10 \mathrm{~mm}$. The other 38 papers were case reports with adrenal 
myelolipoma and CAH, including 42 cases with $21 \mathrm{OHD}(10,22,25-63)$. We identified 10 cases with other types of CAH than $21 \mathrm{OHD}$ with myelolipoma. These cases were not included in the analysis due to low numbers; nine had 17 $\alpha$-hydroxylase deficiency $(59,64-69)$ and one $11 \beta$ - dehydrogenase deficiency (70). For the same reason four case reports with adrenal cortical cancer and 21OHD also were excluded (71-74). A fifth case with cortical cancer and CAH was published autumn 2019 and was a mixed tumor with myelolipoma and included in Table 3 (63).

Figure 1 shows the flow diagram for the searches. Table 1 reports the main characteristic for the six studies with the prevalence of adrenal tumors in CAH. Three of these studies had also included five patients with other enzyme deficiencies than 21OHD. Four of these five patients $(75 \%)$ with other enzyme deficiencies than 210 HD had an adrenal tumor.

\section{Meta-Analysis}

The prevalence of adrenal tumors ( $\geq 5$ and $\geq 10 \mathrm{~mm}$, respectively) in CAH was $29.3 \%$ (19.5\%) and in 21OHD 28.4\% (18.3\%). When only studies with verified CYP21A2 mutations were included the prevalence was $23.6 \%(16.7 \%)$ (Table 1$)$. The prevalence of myelolipoma in $\mathrm{CAH}$ was $7.4 \%$ and in patients with verified $C Y P 21 A 2$ mutations $8.2 \%$. The prevalence of myelolipoma when including only the two largest studies with unselected patients with $\mathrm{CAH}(10,22)$ was $10.1 \%$ (15 of 148), 95\% CI [5.3-15.0], diagnosed at age 40 (19-65) years. This is significant higher than the estimated frequency of myelolipoma in the normal population of 40 years which is estimated to $0.32 \%, 95 \%$ CI [-1.3-1.7].

The proportion of myelolipoma in the adrenal tumors was $25.4 \%$ and raised to $36.6 \%$ when only the studies with verified CYP21A2 mutations were included (Table 1). A pheochromocytoma with a diameter $165 \mathrm{~mm}(10)$ and another of $28 \mathrm{~mm}(22)$ were reported in two separate studies. The other cohort studies only reported the type of tumor if the patient 
had a large tumor and had had an adrenalectomy $(9,21)$. No other etiology than benign adenoma, hyperplasia or myelolipoma were reported in these studies. The median age at tumor diagnosis was 38.0 (12-62) years and there were more tumors in males than in females $37.9 \%$ vs. $22.1 \%, \mathrm{P}<0.05$ (Table 2 ). Tumors were equally frequently reported in the $\mathrm{SW}$ as the SV phenotype (40.9\% vs $45.5 \%, \mathrm{P}>0.5)$. Five of the studies had data on whether the tumors were bilateral or not and of these $22.7 \%$ reported bilateralism. Most tumors were found on the left side (56.8\%). Nermoen et al. (10) and El-Maoche et al. (22) had not published information on tumor side but data were provided after contact with the corresponding authors. The median diameter of the tumors was 24.0 (4-165) mm (Table 2). Four of the studies used computed tomography (CT) and two magnetic resonance imaging (MR)(Table 2).

Data on myelolipoma and CAH was from 42 case reports with 21OHD (25-61) and 15 cases from two of the prevalence studies $(10,22)$ (Table 3$)$. The case with myelolipoma in the article by Jaresch et al.(9) was not included due to missing data. Nermoen et al. had published data on one patient in two publications but we included the patient only once $(10,43)$. Of the 57 cases with $21 \mathrm{OHD}$ and concomitant myelolipoma $46 \%$ were asymptomatic and $33 \%$ had abdominal or flank pain (Table 3). Compared to CAH patients with adrenal adenoma the CAH patients with myelolipoma were older (44 vs 33 years, $\mathrm{P}<0.05)$, had larger tumors (102 vs $10 \mathrm{~mm}, \mathrm{P}<0.005)$, were more often bilateral (59.6\% vs $10.7 \%, \mathrm{P}<0.05)$ and occurred more often in men, however, this was not significant $(66.7 \%$ vs $35.7 \% \mathrm{P}=0.3)$. Almost all patients with myelolipoma had a late diagnosed or poorly managed CAH $(95.7 \%)$.

\section{Discussion}


This is the first systematic review and meta-analysis of the prevalence of adrenal tumors in CAH. We found a high prevalence of adenomas and myelolipomas in this young population of mainly $21 \mathrm{OHD}$ and adrenal imaging in patients with CAH may be considered.

An increasing number of case reports of $\mathrm{CAH}$ with myelolipoma have been published the last few years. We found that the $\mathrm{CAH}$ patients have more than 30 times $(10.1 \%$ vs $0.32 \%)$ increased risk of having myelolipoma compared to the general population. Does it have any clinical relevance to diagnose a myeloma in a CAH patient? Myelolipomas are benign slow growing tumors that often have been interpreted as malignant and the patients have been adrenalectomized unnecessarily (9). Even if the tumors is above $4 \mathrm{~cm}$ it need not to be removed. To avoid this, it is important that both the patients and the clinicians are aware of whether a myelolipoma is present or not. The diagnosis is normally done by the characteristic radiological appearance with round, sharp-demarcated lesion with presence of fatty foci with attenuation values between $-30 \mathrm{HU}$ to $-100 \mathrm{HU}(75)$. However, very large myelolipomas have an increased risk of hemorrhage and elective removal could be considered if they exceed 10 $\mathrm{cm}$ (76). Therefore, we suggest that CAH may be considered in every patient with a myelolipoma. In the review by Decmann et al. $10 \%$ of patients with myelolipoma had concurrent $\mathrm{CAH}(12)$.

It is well known that increased ACTH levels act as a growth factor on adrenal cells resulting in large adrenals. Whether ACTH hypersecretion also cause tumor growth is uncertain, but may be one reason for the high frequency of myelolipomas and adenomas in CAH. However, the etiology of myelolipoma growth is largely unknown, and it has been proposed that development from residual embryonic mesenchymal tissue in the adrenal glands, or metaplasia of reticuloendothelial cells, is a result of chronic stress (76). It has also been postulated that ACTH elevation might induce transformation of adrenal tissue into myeloid 
tissue (77). At least two case reports have investigated steroid receptors in myelolipomas. Hagiwara et al. did not find overexpression of ACTH or androgen receptors in a giant myelolipoma in a woman with CAH (42). However, Almeida et al. detected increased expression of ACTH (Melanocortin 2 receptor) and androgen receptors in giant bilateral myelolipomas from patients with $\mathrm{CAH}$. This systematic review and meta-analysis support the theory that chronic ACTH stimulation could have a direct role in the development of adrenal lesions, especially myelolipomas.

The data for the meta-analysis were somewhat limited since only six studies had investigated the frequency of adrenal tumors in $\mathrm{CAH}$, and only two of them had a larger study population with 63 and 88 participants, respectively $(10,22)$, compared to 4-26 participants in the other studies $(9,21,23,24)$. However this is the best information we have to date on this rare disease and prevalence of adrenal adenoma. The meta-analysis showed that $28.1 \%$ of patients with $210 H D$ had at least one adrenal tumor, and when including only those with genetically verified $21 \mathrm{OHD}$ the prevalence fell slightly to $23.2 \%$. Jaresch et al. found a very high prevalence of adrenal tumors of $80 \%(9)$, by examining $22 \mathrm{CAH}$ patients with $\mathrm{CT}$ and defining an adrenal mass over $5 \mathrm{~mm}$ as a tumor. Half of the tumors were only $5-9 \mathrm{~mm}$ and thus macronodular hyperplasia may have been interpreted as adrenal tumors. If Jaresch et al. had defined an adrenal tumor as $\geq 10 \mathrm{~mm}$ the prevalence would still be high at $40.9 \%$ (Table 1).

Normally lesions of $10 \mathrm{~mm}$ in size or more are defined as adrenal tumors (78). However, both Reisch et al. and El-Maouche et al. $(22,24)$ defined a mass over $5 \mathrm{~mm}$ as a tumor. We obtained additional information from the authors of the exact numbers of tumors $\geq 10 \mathrm{~mm}$ and still the prevalence of adrenal tumors in $\mathrm{CAH}$ was considerable higher than reported in the general population. The prevalence in the general population of silent adrenal adenomas has 
been estimated to $<1 \%$ in the young, $2-4 \%$ in the middle ages (50s) and more than $10 \%$ in the elderly (13). The median age in the CAH group was 36 year when the tumors were diagnosed and with a prevalence of $16.5 \%$ (adenoma size $\geq 10 \mathrm{~mm}$ ) there was at least a five-fold increase compared to the general population. Moreover, a large proportion of the adrenal tumor in CAH were myelolipomas. Reisch et al. used MRI, and did not report any myelolipomas in their study (24). However, the applied technique did not include fat suppression imaging which could have discriminated myelolipomas from adenomas. In addition, Jaresch et al. used CT and the only myelolipoma they reported was first diagnosed after adrenalectomy due to size and only mentioned in the discussion (9). Furthermore, we have seen several unpublished case reports being presented at different meeting the last few years. We therefore postulate that the proportion of myelolipomas in 21OHD may be underestimated. We suggest that in the follow-up of the adult patients with $\mathrm{CAH}$ an imaging of the adrenals may be considered once in adulthood and perhaps regularly every five to ten year depending on the result of the imaging. Especially if abdominal pain is present imaging could be considered since many of the myelolipomas presented with abdominal pain. CT should be considered as the first radiological investigation since MRI do not detect small calcifications that myelolipoma may demonstrate. It is also recommended to use noncontrast CT in all adrenal tumors to determine if the mass is homogenous and lipid-rich and therefore benign (16). An adrenal mass is considered benign when the $\mathrm{HU}$ are $\leq 10$ and the tumor is homogenous and smaller than $4 \mathrm{~cm}$, then no further imaging is required (16). Ultrasound is not a good screening method if the adrenal tumors are small since they are located deep within the abdomen and surrounded by fat (75). However, in the follow-up of a large myelolipoma or adenoma ultrasound or MRI could be the preferred imaging to avoid unnecessary ionizing radiation. In the case reports with myelolipoma near all the patients had a poorly treated or late diagnosed $\mathrm{CAH}$ with high $\mathrm{ACTH}$-levels and optimization of the 
glucocorticoid replacement is warranted. If the patient has undiagnosed CAH with glucocorticoid and/or mineralocorticoid deficiency surgery could be fatal due to the risk of developing an adrenal crisis per- or postoperative $(79,80)$.

\section{Conclusion}

Patients with $\mathrm{CAH}$ had a considerable higher prevalence of adrenal tumors, particularly myelolipomas, compared to the general population and at a younger age. In addition, almost all patients with $\mathrm{CAH}$ and concurrent myelolipoma had late diagnosed or poorly controlled CAH. Physicians and the patients should be aware of the increased prevalence to avoid unnecessary surgery of benign tumors such as myelolipomas. Imaging in the follow-up of the patients with CAH may be considered, especially if the patient has abdominal pain since this is a common presentation of myelolipomas. Moreover, CAH may be considered in every patient with a myelolipoma.

\section{References}

1. Arlt W, Willis DS, Wild SH, et al. Health status of adults with congenital adrenal hyperplasia: a cohort study of 203 patients. J Clin Endocrinol Metab. 2010;95:51105121.

2. Gidlof S, Falhammar $\mathrm{H}$, Thilen $\mathrm{A}$, et al. One hundred years of congenital adrenal hyperplasia in Sweden: a retrospective, population-based cohort study. Lancet Diabetes Endocrinol. 2013;1:35-42.

3. Bulsari K, Falhammar H. Clinical perspectives in congenital adrenal hyperplasia due to 11beta-hydroxylase deficiency. Endocrine. 2017;55:19-36.

4. Al Alawi AM, Nordenstrom A, Falhammar H. Clinical perspectives in congenital adrenal hyperplasia due to 3beta-hydroxysteroid dehydrogenase type 2 deficiency. Endocrine. 2019;63:407-421.

5. Auchus RJ. Steroid 17-hydroxylase and 17,20-lyase deficiencies, genetic and pharmacologic. J Steroid Biochem Mol Biol. 2017;165:71-78. 
6. Miller WL. Mechanisms in endocrinology: Rare defects in adrenal steroidogenesis. Eur J Endocrinol. 2018;179:R125-R141.

7. Dean B, Chrisp GL, Quartararo M, et al. P450 oxidoreductase deficiency: A systematic review and meta-analysis of genotypes, phenotypes and their relationships. J Clin Endocrinol Metab. 2019;Dec 11: doi: 10.1210/clinem/dgz255.

8. Falhammar $\mathrm{H}$, Thoren $\mathrm{M}$. Clinical outcomes in the management of congenital adrenal hyperplasia. Endocrine. 2012;Jun;41(3):355--373.

9. Jaresch S, Kornely E, Kley HK, Schlaghecke R. Adrenal Incidentaloma and patients with homozygous or heterozygous congenital adrenal hyperplasia. J Clin Endocrinol Metab. 1992;74:685-689.

10. Nermoen I, Rørvik J, Holmedal SH, et al. High frequency of adrenal myelolipomas and testicular adrenal rest tumours in adult Norwegian patients with classical congenital adrenal hyperplasia because of 21-hydroxylase deficiency. Clin Endocrinol (Oxf). 2011;75:753-759.

11. Speiser PW, Arlt W, Auchus RJ, et al. Congenital Adrenal Hyperplasia Due to Steroid 21-Hydroxylase Deficiency: An Endocrine Society Clinical Practice Guideline. J Clin Endocrinol Metab. 2018;103:4043-4088.

12. Decmann A, Perge P, Toth M, Igaz P. Adrenal myelolipoma: a comprehensive review. Endocrine. 2018;59:7-15.

13. Arnaldi G, Boscaro M. Adrenal incidentaloma. Best Pract Res Clin Endocrinol Metab. 2012;26:405-419.

14. Patrova J, Jarocka I, Wahrenberg H, Falhammar H. Clinical Outcomes in Arenal Incidentaloma: Experience from one center. Endocr Pract. 2015;21:870-877.

15. Falhammar H, Torpy DJ. Congenital Adrenal Hyperplasia due to 21-Hydroxylase Deficiency Presentig as Adrenal Incidentaloma: A Systemtiv Review and Metanalysis. Endocr Pract. 2016;22:736-752.

16. Fassnacht $M$, Arlt W, Bancos I, et al. Management of adrenal incidentalomas: European Society of Endocrinology Clinical Practice Guideline in collaboration with the European Network for the Study of Adrenal Tumors. Eur J Endocrinol. 2016;175:G1-G34.

17. Falhammar $\mathrm{H}$, Wedell A, Nordenstrom A. Biochemical and genetic diagnosis of 21hydroxylase deficiency. Endocrine. 2015;50:306-314.

18. Moher D, Liberati A, Tetzlaff J, Altman DG. Preferred reporting items for systematic reviews and meta-analyses: the PRISMA statement. BMJ. 2009;339:b2535.

19. Song JH, Chaudhry FS, Mayo-Smith WW. The incidental adrenal mass on CT: prevalence of adrenal disease in 1,049 consecutive adrenal masses in patients with no known malignancy. AJR Am J Roentgenol. 2008;190:1163-1168.

20. Jaresch S, Schlaghecke R, Jungblut R, Kruskemper HL, Kley HK. [Silent adrenal gland tumors in patients with adrenogenital syndrome]. Klin Wochenschr. 1987;65:627633.

21. Falke TH, van Seters AP, Schaberg A, Moolenaar AJ. Computed tomography in untreated adults with virilizing congenital adrenal cortical hyperplasia. Clin Radiol. 1986;37:155-160.

22. El-Maouche D, Hannah-Shmouni F, Mallappa A, Hargreaves CJ, Avila NA, Merke DP. Adrenal morphology and associated comorbidities in congenital adrenal hyperplasia. Clin Endocrinol (Oxf). 2019;91:247-255. 
23. Azziz R, Kenney PJ. Magnetic resonance imaging of the adrenal gland in women with late-onset adrenal hyperplasia. Fertil Steril. 1991;56:142-144.

24. Reisch N, Scherr M, Flade $\mathrm{L}$, et al. Total adrenal volume but not testicular adrenal rest tumor volume is associated with hormonal control in patients with 21-hydroxylase deficiency. J Clin Endocrinol Metab. 2010;95:2065-2072.

25. Schindler H. [Myelolipoma of the adrenal gland in adrenogenital syndrome]. Wien Med Wochenschr. 1975;725:695-697.

26. Boudreaux D, Waisman J, Skinner DG, Low R. Giant adrenal myelolipoma and testicular interstitial cell tumor in a man with congenital 21-hydroxylase deficiency. Am J Surg Pathol. 1979;3:109-123.

27. Oliva A, Duarte B, Hammadeh R, Ghosh L, Baker RJ. Myelolipoma and endocrine dysfunction. Surgery. 1988;103:711-715.

28. Miyazaki Y, Yoshida M, Doi J. [A case of adrenal myelolipoma associated with adrenogenital syndrome]. [Japanese]. Hinyokika Kiyo - Acta Urologica Japonica. 1990;36:35-39.

29. Murakami C, Ishibashi M, Kondo $M$, et al. Adrenal myelolipoma associated with congenital adrenal 21-hydroxylase deficiency. Intern Med. 1992;31:803-806.

30. Iwamoto $\mathrm{T}$, Yajima M, Tanaka H, Minagawa $\mathrm{N}$, Osada $\mathrm{T}$. [A case report: reversible male infertility due to congenital adrenal hyperplasia]. [Japanese]. Nippon Hinyokika Gakkai Zasshi - Japanese Journal of Urology. 1993;84:2031-2034.

31. Ravichandran R, Lafferty F, McGinniss MJ, Taylor HC. Congenital adrenal hyperplasia presenting as massive adrenal incidentalomas in the sixth decade of life: report of two patients with 21-hydroxylase deficiency. J Clin Endocrinol Metab. 1996;81:17761779.

32. Umpierrez MB, Fackler S, Umpierrez GE, Rubin J. Adrenal myelolipoma associated with endocrine dysfunction: review of the literature. Am J Med Sci. 1997;314:338341.

33. Adesokan A, Adegboyega PA, Cowan DF, Kocurek J, Neal DE, Jr. Testicular "tumor" of the adrenogenital syndrome: a case report of an unusual association with myelolipoma and seminoma in cryptorchidism. Cancer. 1997;80:2120-2127.

34. Allison KH, Mann GN, Norwood TH, Rubin BP. An unusual case of multiple giant myelolipomas: clinical and pathogenetic implications. Endocr Pathol. 2003;14:93-100.

35. Mathew J, Menon PS, Shah NS. An elderly lady in shock. J Postgrad Med. 2005;51:5153.

36. Kalidindi RS, Hattingh L. Bilateral giant adrenal myelolipomas. Abdom Imaging. 2006;31:125-127.

37. Treska V, Wirthova M, Hadravska S, et al. [Giant bilateral adrenal myelolipoma associated with congenital adrenal hyperplasia]. [German]. Zentralbl Chir. 2006;131:80-83.

38. Sakaki M, Izaki H, Fukumori T, Taue R, Kishimoto T, Kanayama HO. Bilateral adrenal myelolipoma associated with adrenogenital syndrome. Int J Urol. 2006;13:801-802.

39. Rodriguez-Vallejo FG-P, Fj. Two siblings with untreated CYP21 deficiency and giant myelolipomas - Case report and review of the literature Endocrinologist. 2006;16(3) 172-178.

40. Rajput RM, Bhansali AM, Khandelwal NM, Radotra BDM, PhD +. Evolution of Adrenal Myelolipoma in a Patient With Congenital Adrenal Hyperplasia. [Report].

Endocrinologist. 2007;17:200-201. 
41. Nigawara T, Kageyama K, Sakihara S, et al. A male case of nonclassical 21-hydroxylase deficiency first manifested in his sixties with adrenocortical incidentaloma. Endocr J. 2008;55:291-297.

42. Hagiwara H, Usui T, Kimura T, et al. Lack of ACTH and androgen receptor expression in a giant adrenal myelolipoma associated with 21-hydroxylase deficiency. Endocr Pathol. 2008;19:122-127.

43. Nermoen I, Følling I, Vegge K, et al. Two adults with adrenal myelolipoma and 21hydroxylase deficiency. Case Report Med. 2009;2009:916891.

44. Mermejo LMEJ, Jorge ; Saggioro, Fabiano Pinto ; Tucci Junior, Silvio ; Castro, Margaret de ; Moreira, Ayrton Custódio ; Elias, Paula C. Lamparelli. Giant adrenal myelolipoma associated with 21-hydroxylase deficiency: unusual association mimicking an androgen-secreting adrenocortical carcinoma Arquivos Brasileiros de Endocrinologia \& Metabologia. 2010;54(4) 419-424.

45. Ioannidis O, Papaemmanouil S, Chatzopoulos S, et al. Giant bilateral symptomatic adrenal myelolipomas associated with congenital adrenal hyperplasia. Pathol Oncol Res. 2011;17:775-778.

46. German-Mena E, Zibari GB, Levine SN. Adrenal myelolipomas in patients with congenital adrenal hyperplasia: review of the literature and a case report. Endocr Pract. 2011;17:441-447.

47. McGeoch SC, Olson S, Krukowski ZH, Bevan JS. Giant bilateral myelolipomas in a man with congenital adrenal hyperplasia. J Clin Endocrinol Metab. 2012;97:343-344.

48. Garduno-Garcia Jde J, Arjona Villicana R, Pimentel L, Perez Diaz I, Gomez-Perez FJ. Late-occurring giant adrenal myelolipoma in a patient with congenital adrenal hyperplasia. Endocrinologia y nutricion : organo de la Sociedad Espanola de Endocrinologia y Nutricion. 2013;60:e33-34.

49. Ferreira F, Martins JM, do Vale S, Esteves R, Nunes G, Carmo I. Rare and severe complications of congenital adrenal hyperplasia due to 21-hydroxylase deficiency: a case report. J Med Case Rep. 2013;7:39.

50. Sancak SA, H ; Aydin, H ; Tukun, A ; Mantoglu, B ; Ender, O ; Karip, B ; Okuducu, M ; Baskent, A ; Alp, T; Memisoglu, K. Bilateral adrenal myelolipoma in a 46 XX DSD patient with congenital adrenal hyperplasia due to 21-hydroxylase deficiency. Case report Acta Endocrinologica-Bucharest. 2013;9(1):109-119.

51. Almeida MQ, Kaupert LC, Brito LP, et al. Increased expression of ACTH (MC2R) and androgen $(A R)$ receptors in giant bilateral myelolipomas from patients with congenital adrenal hyperplasia. BMC Endocr Disord. 2014;14:42.

52. Alvarez JF, Goldstein L, Samreen N, et al. Giant adrenal myelolipoma. J Gastrointest Surg. 2014;18:1716-1718.

53. Al-Bahri S, Tariq A, Lowentritt B, Nasrallah DV. Giant bilateral adrenal myelolipoma with congenital adrenal hyperplasia. Case reports in surgery. 2014;2014:728198.

54. Kale G, Pelley EM, Davis DB. Giant myelolipomas and inadvertent bilateral adrenalectomy in classic congenital adrenal hyperplasia. Endocrinology, diabetes \& metabolism case reports. 2015;2015:150079.

55. O'Shea T, Crowley RK, Farrell M, et al. Growth of a progesterone receptor-positive meningioma in a female patient with congenital adrenal hyperplasia. Endocrinology, diabetes \& metabolism case reports. 2016;2016:16-0054.

56. Okamoto $S$. An adult case of congenital adrenal hyperplasia due to 21-hydroxylase deficiency associated with bilateral adrenal myelolipoma:An 8-year observation of 
clinical characteristics during steroid replacement therapy. Journal of Nara Medical Association 1998;49:147-155.

57. Altieri VM, Altieri B, Castellucci R, et al. Leydig cell tumour and giant adrenal myelolipoma associated with adrenogenital syndrome: a case report with a review of the literature. Urologia. 2016;83:43-48.

58. Feng $X$, Kline G. Massive adrenal incidentalomas and late diagnosis of congenital adrenal hyperplasia in prostate cancer. Endocrinology, diabetes \& metabolism case reports. 2017;2017:17-0108.

59. Liu Q, Wang LA, Su J, et al. Giant bilateral adrenal myelolipomas in two Chinese families with congenital adrenal hyperplasia. Endocrine connections. 2018;7(11):1136-1141.

60. Kim HJ. Adrenal myelolipoma in association with congenital adrenal hyperplaisia. Endocrine. 2019;63:403-404.

61. Suchartlikitwong S, Jasti R, Lado-Abeal J, Rivas Mejia AM. Bilateral adrenal myelolipomas presenting as acute adrenal insufficiency in an adult with congenital adrenal hyperplasia. BMJ Case Rep. 2019;12(2).

62. Piskinpasa H, Ciftci Dogansen S, Kusku Cabuk F, et al. Bilateral adrenal and testicular mass in a patient with congenital adrenal hyperplasia. Acta Endocrinol (Buchar). 2019;5:113-117.

63. Pakalniskis MG, Ishigami K, Pakalniskis BL, Fujita N. Adrenal collision tumour comprised of adrenocortical carcinoma and myelolipoma in a patient with congenital adrenal hyperplasia. J Med Imaging Radiat Oncol. 2019;Oct 1. doi: 10.1111/17549485.12961.

64. Condom E, Villabona CM, Gomez JM, Carrera M. Adrenal myelolipoma in a woman with congenital 17-hydroxylase deficiency. Arch Pathol Lab Med. 1985;109:11161117.

65. Sasano H, Masuda T, Ojima M, Fukuchi S, Sasano N. Congenital 17 alpha-hydroxylase deficiency: a clinicopathologic study. Hum Pathol. 1987;18:1002-1007.

66. Nagai T, Imamura M, Honma M, Murakami M, Mori M. 17alpha-hydroxylase deficiency accompanied by adrenal myelolipoma. Intern Med. 2001;40:920-923.

67. Patocs A, Liko I, Varga I, et al. Novel mutation of the CYP17 gene in two unrelated patients with combined 17alpha-hydroxylase/17,20-lyase deficiency: demonstration of absent enzyme activity by expressing the mutant CYP17 gene and by threedimensional modeling. J Steroid Biochem Mol Biol. 2005;97:257-265.

68. Yang F, Zhao Y, LV J, Sheng X, Wang L. A new compound heterozygous mutation in a female with 17alpha-hydroxylase/17,20-lyase deficiency, slipped capital femoral epiphysis, and adrenal myelolipoma. Gynecol Endocrinol. 2019;35:385-389.

69. Soveid M GAR-JG. Seventeen Alpha-Hydroxylase Deficiency Associated with Absent Gonads and Myelolipoma: A Case Report and Review of Literature. Iran J Med Sci 2016; 41: 543-547.

70. John M MSK, Shah N S, Menon P S. Congenital adrenal hyperplasia 11ß-hydroxylase deficiency: two cases managed with bilateral adrenalectomy. Singapore Med Case Report J. 2009;50(2):e68-e70.

71. Bauman A, Bauman CG. Virilizing adrenocortical carcinoma. Development in a patient with salt-losing congenital adrenal hyperplasia. JAMA. 1982;248:3140-3141. 
72. Hayashi $M$, Kataoka $Y$, Sugimura $Y$, et al. A 68-year-old phenotypically male patient with 21-hydroxylase deficiency and concomitant adrenocortical neoplasm producing testosterone and cortisol. Tohoku J Exp Med. 2013;231:75-84.

73. Varma T, Panchani R, Goyal A, Maskey R. A case of androgen-secreting adrenal carcinoma with non-classical congenital adrenal hyperplasia. Indian J Endocrinol Metab. 2013;17:S243-245.

74. Libe $\mathrm{R}$, Arlt $\mathrm{W}$, Louiset $\mathrm{E}$, et al. A feminizing adrenocortical carcinoma in the context of a late onset 21-hydroxylase deficiency. J Clin Endocrinol Metab. 2014;99:19431944.

75. Farrugia FA, Martikos G, Surgeon C, et al. Radiology of the adrenal incidentalomas. Review of the literature. Endocr Regul. 2017;51:35-51.

76. Kenney PJ, Wagner BJ, Rao P, Heffess CS. Myelolipoma: CT and pathologic features. Radiology. 1998;208:87-95.

77. Selye $\mathrm{H}$, Stone $\mathrm{H}$. Hormonally induced transformation of adrenal into myeloid tissue. Am J Pathol. 1950;26:211-233.

78. Mantero F, Masini AM, Opocher G, Giovagnetti M, Arnaldi G. Adrenal incidentaloma: an overview of hormonal data from the National Italian Study Group. Horm Res. 1997;47:284-289.

79. Nagasaka S, Kubota K, Motegi T, et al. A case of silent 21-hydroxylase deficiency with persistent adrenal insufficiency after removal of an adrenal incidentaloma. Clin Endocrinol (Oxf). 1996;44:111-116.

80. Rushworth RL, Torpy DJ, Falhammar H. Adrenal Crisis. N Engl J Med. 2019;381:852861. 


\section{Legends for Figures and Tables}

Figure 1. Flow Diagram of Process of Systematic Review

Table 1. Prevalence of Adrenal Tumors in Patients with Congenital Adrenal Hyperplasia

Table 2. Meta-Analysis of 59 Cases with 21-hydroxylase deficiency and Adrenal Tumors

Table 3. Clinical Characteristics of Myelolipoma in Congenital Adrenal Hyperplasia due to 21-hydroxylase deficiency 
Figure 1

676 articles identified through database searching
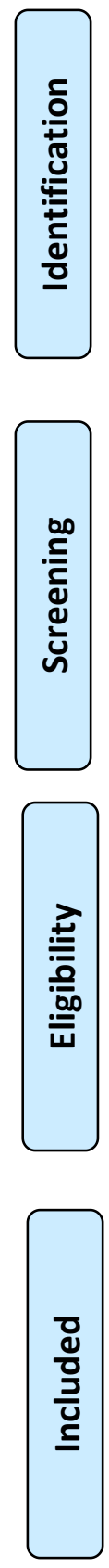

\section{6}

\section{1 additional record identified} through other sources

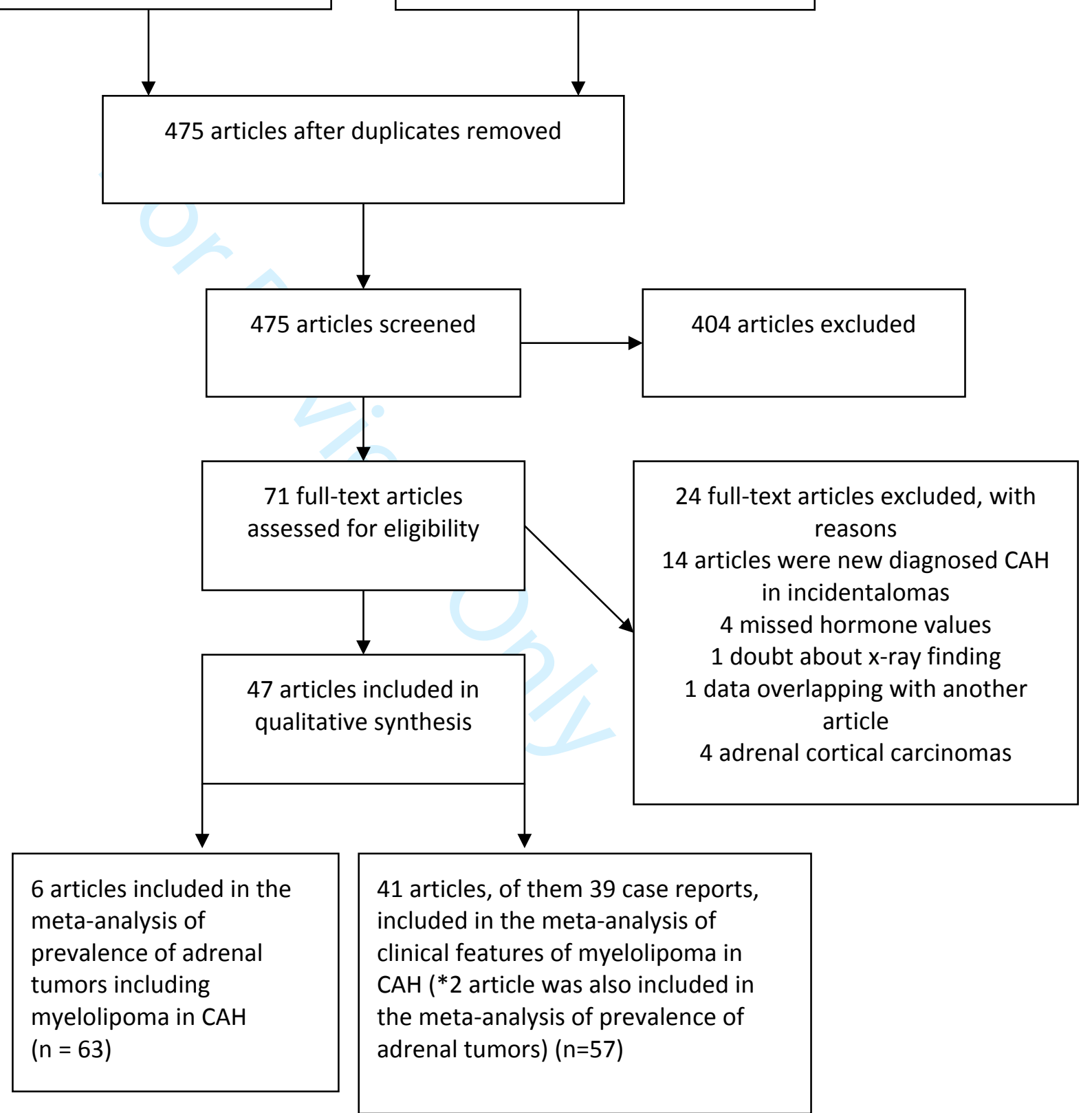




\begin{tabular}{|c|c|c|c|c|c|c|}
\hline First author & Year & Country & Title & Definition of tumor & $\begin{array}{l}\text { CAH cases with adrenal } \\
\text { tumors of total } \\
\text { screened CAH cases }\end{array}$ & $\begin{array}{l}\text { CAH cases with adrenal } \\
\text { tumors } \geq 10 \mathrm{~mm} \text { of total } \\
\text { screened CAH cases }\end{array}$ \\
\hline El-Maouche D (22) & 2019 & USA & $\begin{array}{l}\text { Adrenal morphology and associated comorbities } \\
\text { in congenital adrenal hyperplasia }\end{array}$ & $\geq 5 \mathrm{~mm}$ & $19 / 88(21.6 \%)$ & $15 / 88$ \\
\hline Nermoen I (10) & 2011 & Norge & $\begin{array}{l}\text { High frequency of adrenal myelolipoma and testicular } \\
\text { adrenal rest tumors in adult Norwegian with classical } \\
\text { congenital adrenal hyperplasia due to 21-hydroxylase } \\
\text { deficiency }\end{array}$ & $\geq 10 \mathrm{~mm}$ & $7 / 62(11.3 \%)$ & $7 / 62(11.3 \%)$ \\
\hline Reisch N (24) & 2010 & Germany & $\begin{array}{l}\text { Total adrenal volume but not testicular adrenal rest } \\
\text { tumor volume is asscociated with hormonal control } \\
\text { in patients with 21-hydroxylase deficiency }\end{array}$ & $\geq 5 \mathrm{~mm}$ & $15 / 26(57.7 \%)$ & $7 / 26(26.9 \%)$ \\
\hline Jaresch S (9) & 1992 & Germany & $\begin{array}{l}\text { Adrenal incidentaloma and patients with } \\
\text { homozygous or heterozygous congenital adrenal } \\
\text { hyperplasia }\end{array}$ & $\geq 5 \mathrm{~mm}$ & $18 / 22(81.8 \%)^{*}$ & $9 / 22(40.9 \%)$ \\
\hline Azziz R (23) & 1991 & USA & $\begin{array}{l}\text { Magnetic resonance imaging of the adrenal } \\
\text { gland in women with late- onset adrenal hyperplasia }\end{array}$ & $\geq 10 \mathrm{~mm}$ & $1 / 4(25.0 \%)^{* *}$ & $1 / 4(25.0 \%)^{* *}$ \\
\hline Falke TH (21) & 1986 & $\begin{array}{l}\text { The } \\
\text { Nether- } \\
\text { lands }\end{array}$ & $\begin{array}{l}\text { Computed tomography in untreated adults with } \\
\text { virilizing congenital adrenal hyperplasia }\end{array}$ & $\begin{array}{l}\text { Only definition of adrenal } \\
\text { enlargement:Thickening of } \\
\text { limb junction }>10 \mathrm{~mm}\end{array}$ & $3 / 13(23.1 \%)^{* * *}$ & $3 / 13(23.1 \%)^{* * *}$ \\
\hline \multicolumn{5}{|c|}{ Prevalence of adrenal tumors in CAH (all studies) } & $63 / 215(29.3 \%)$ & 42/215(19.5\%) \\
\hline \multicolumn{7}{|c|}{ Prevalence of adrenal tumors in CAH due to $210 \mathrm{HD}$ (all studies) } \\
\hline \multicolumn{7}{|c|}{ Prevalence of adrenal tumors in CAH due to 210HD ( CAH verified with CYP21A2 mutations) } \\
\hline \multicolumn{7}{|c|}{ Prevalence of myeolipoma in CAH due to $210 \mathrm{HD}$ (all studies) } \\
\hline \multicolumn{7}{|c|}{ Prevalence of myelolipoma in CAH due to 210HD (CAH verified with CYP21A2 mutations) } \\
\hline \multicolumn{7}{|c|}{ Proportion myelolipom in adrenal tumors in CAH due to 210HD (CAH verified with CYP21A2 mutations) } \\
\hline \multicolumn{7}{|c|}{ Proportion myelolipom in adrenal tumors in CAH (all studies) } \\
\hline
\end{tabular}

\section{ND, no data}

*Two were diagnosed with $3 \beta$-hydroxysteroid dehydrogenase deficiency and $11 \beta$-hydroxylase deficiency and both had adrenal tumors

**One was diagnosed with $11 \beta$-hydroxylase deficiency and had no tumor

***Two were diagnosed with $11 \beta$-hydroxylase deficiency and both had adrenal tumors 


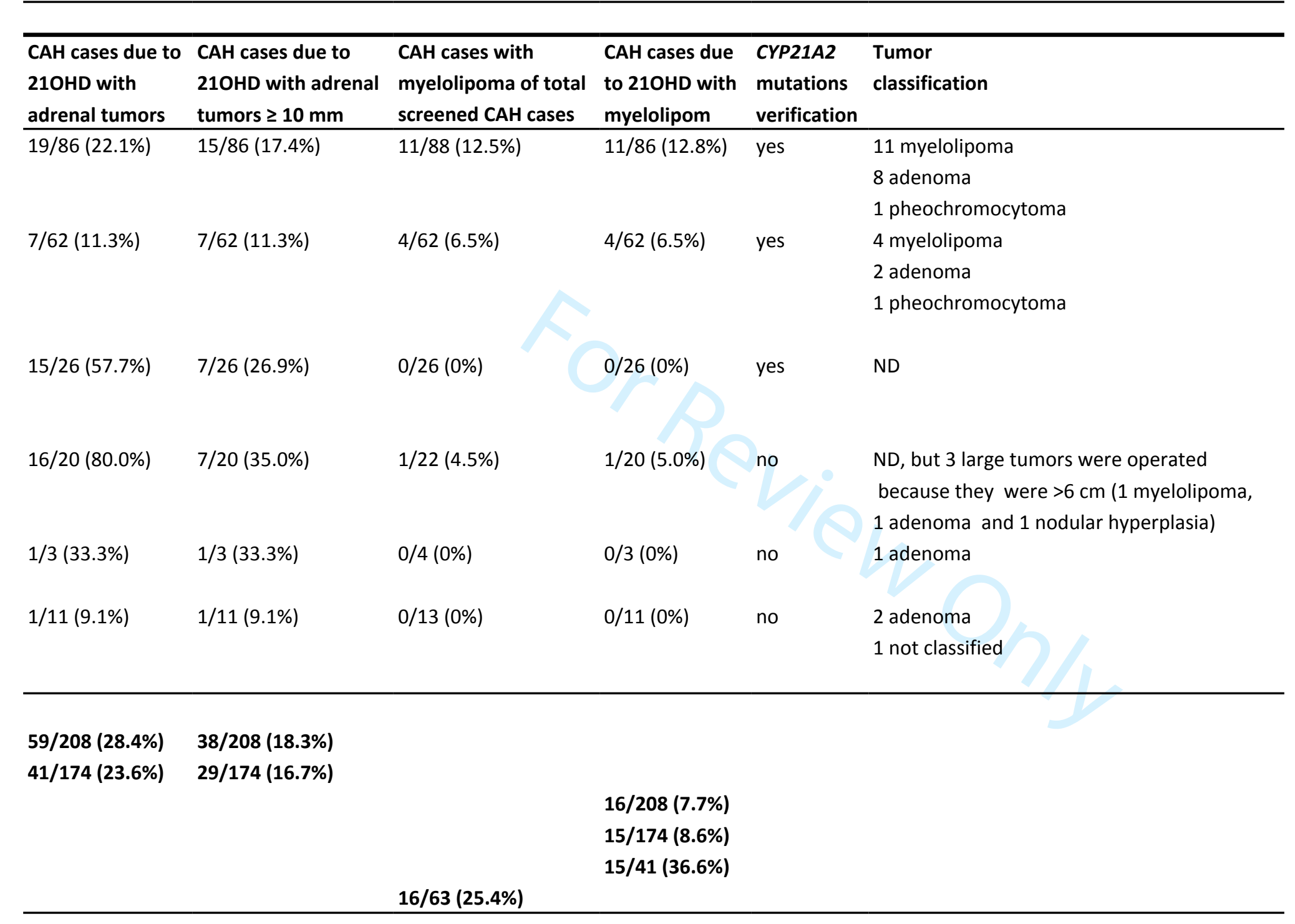




\begin{tabular}{|c|c|c|c|}
\hline $\begin{array}{l}\text { First author and ratio } \\
\text { of patients with tumor } \\
\text { (ref) }\end{array}$ & Imaging modality & $\begin{array}{l}\text { Age at tumor } \\
\text { diagnoses (years) } \\
\text { (median and range } \\
\end{array}$ & $\begin{array}{l}\text { Gender } \\
\mathrm{N}(\%) \\
\end{array}$ \\
\hline El-Maouche D 19/88 (22)*** & $\mathrm{CT}$ & $38.0(16-65)$ & $\begin{array}{l}12 \text { in } 41 \text { male }(29.3 \%) \\
7 \text { in } 47 \text { female }(14.9 \%)\end{array}$ \\
\hline Nermoen I, 7/62 (10)*** & CT with contrast & $38.0(27-58)$ & $\begin{array}{l}5 \text { in } 23 \text { male }(21.7 \%) \\
2 \text { in } 39 \text { female }(5.1 \%)\end{array}$ \\
\hline Reisch N, 15/26 (24) & MR & $\begin{array}{l}\text { ND } \\
\text { [age of total study } \\
\text { population } \\
33.0 \text { years }(18-48) \text { ] }\end{array}$ & $\begin{array}{l}15 \text { in } 25 \text { male (60.0\%) } \\
\text { (no female in study) }\end{array}$ \\
\hline Jaresch S, 16/20 (9) & CT with contrast & $25.0(12-60)$ & $\begin{array}{l}13 \text { in } 15 \text { female }(86.7 \%) \\
3 \text { in } 5 \text { male }(60.0 \%)\end{array}$ \\
\hline Azziz R, 1/3 (23) & MR & 34.0 & $\begin{array}{l}1 \text { in } 3 \text { female (33.3\%) } \\
\text { (no male in study) }\end{array}$ \\
\hline Falke TH, 1/11 (21) & $\mathrm{CT}$ with contrast & 48.0 & $\begin{array}{l}146, X X \text { male with tumor } \\
\text { (gender not stated in } 6 \text { cases) }\end{array}$ \\
\hline Results & & $36.0(12-60)^{*}$ & $\begin{array}{l}36 / 95 \text { male }(37.9 \%)^{* *} \\
23 / 104 \text { female }(22.1 \%)^{* *} \\
P<0.05\end{array}$ \\
\hline
\end{tabular}

\footnotetext{
* Reisch not included. ${ }^{* *}$ Falke not included. ${ }^{* * *}$ Some data obtained after contact with the corresponding : $\mathrm{CT}$, computed tomography, MRI, magnetic resonance imaging, ND, no data, SW, salt wasting. SV, simple vir
} 


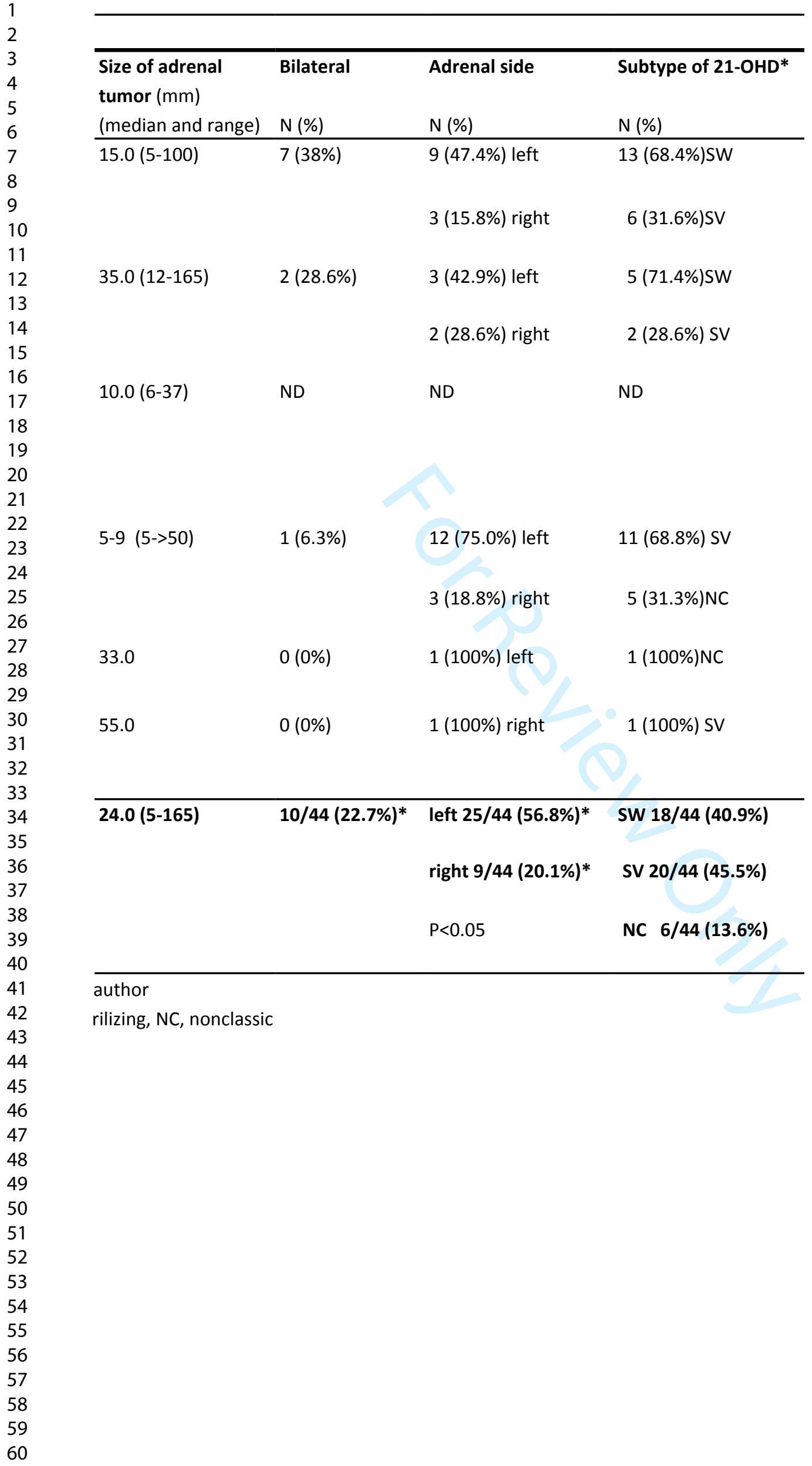




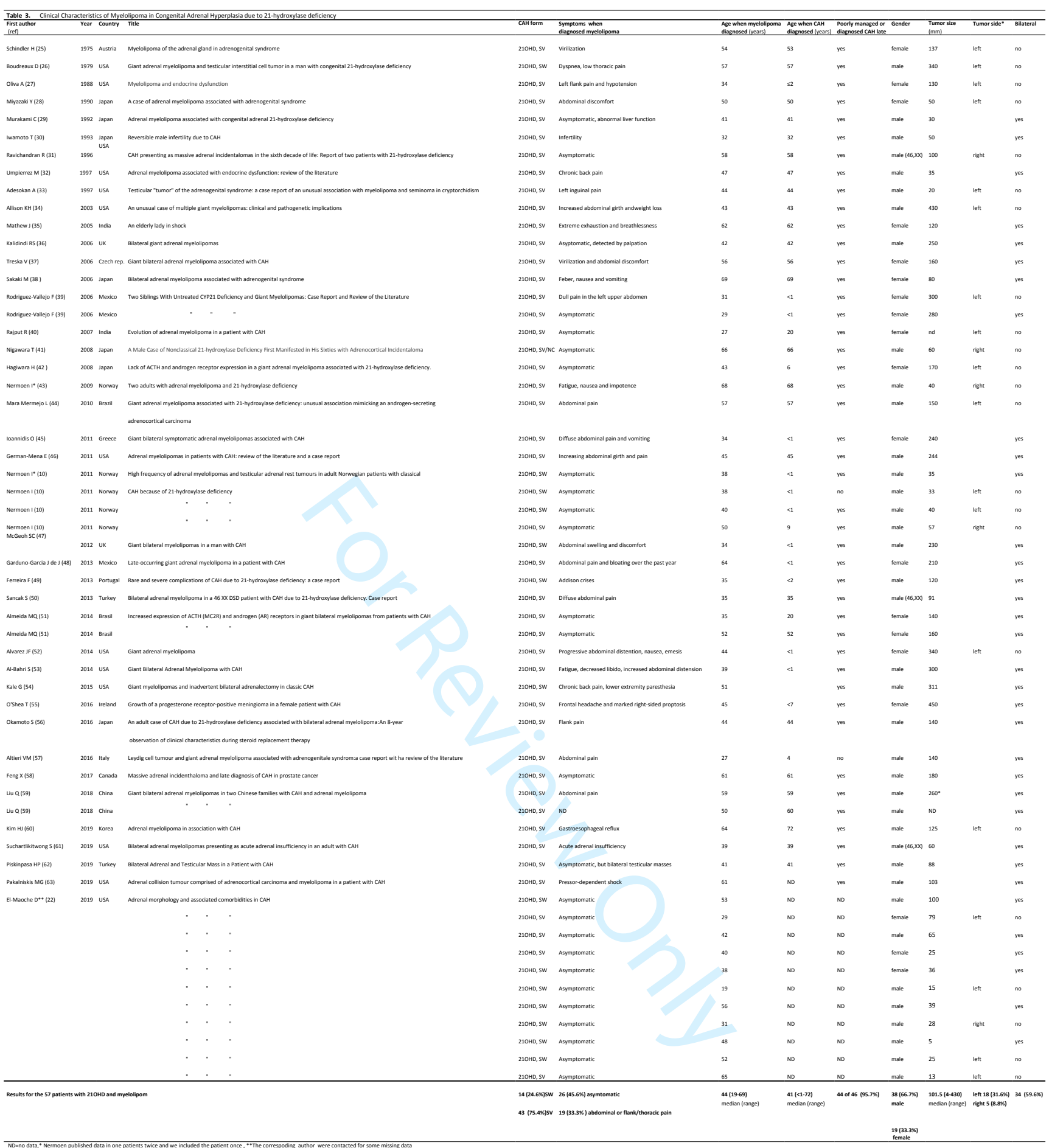

https://mc04.manuscriptcentral.com/aacejournals 